\title{
Fabrication of Transparent Conducting Electrode Pattern by Metal Mesh Method on Stretchable Film Substrate
}

\author{
Gun-Woo Lee1, Dock Young Lee ${ }^{2}$, Byung Chan Lee ${ }^{3}$, Kyungha Baek ${ }^{4}$, \\ Genggongwo Shi ${ }^{5}$, Jeseob Kim5, Lee Soon Park ${ }^{4 *}$, Su Yong Nam6* \\ ${ }^{1}$ Green Ind. Co. Ltd., Changwon, South Korea \\ ${ }^{2}$ ELK Corporation, Daejeon, South Korea \\ ${ }^{3}$ Daegu Technopark, Daegu, South Korea \\ ${ }^{4}$ School of Materials Science and Engineering, Ulsan National Institute of Science and Technology (UNIST), Ulsan, South Korea \\ ${ }^{5}$ CCTech Inc., Hwaseong, South Korea \\ ${ }^{6}$ Department of Graphic Arts Information Engineering, Pukyong National University, Busan, South Korea \\ Email: *lspark@unist.ac.kr, *suynam@pknu.ac.kr
}

How to cite this paper: Lee, G.-W., Lee, D.Y., Lee, B.C., Baek, K., Shi, G., Kim, J., Park, L.S. and Nam, S.Y. (2019) Fabrication of Transparent Conducting Electrode Pattern by Metal Mesh Method on Stretchable Film Substrate. Materials Sciences and Applications, 10, 393-405.

https://doi.org/10.4236/msa.2019.105029

Received: March 29, 2019

Accepted: May 14, 2019

Published: May 17, 2019

Copyright $\odot 2019$ by author(s) and Scientific Research Publishing Inc. This work is licensed under the Creative Commons Attribution International License (CC BY 4.0).

http://creativecommons.org/licenses/by/4.0/

\begin{abstract}
Smart phones have become one of major electronic devices for human being. The easy and rapid exchange of information between man and machine is carried out by the touch screen panel (TSP) installed in the smart phones. Currently the smart phones are widely spread out while displays for automobiles are in the initial stage of developments. Since the automobile displays should fit the curved area of indoor space of the vehicle, the TSPs for automobiles need to be fabricated on the flexible and stretchable substrate film. In this study, we selected the thermoplastic polyurethane film as the substrate film and examined the materials and process for fabrication of metal mesh type transparent conducting electrode films suitable for TSPs of automobile displays. The optimum UV resin system was established by the evaluation of various UV resin formulations in the UV imprinting process to make $3 \times 3.5$ $\mu \mathrm{m}$ trench patterns on the metal mesh type electrode film utilizing the embossed metal mask plate. The Ag paste has also been prepared by synthesis of $\mathrm{Ag}$ nanoparticles and formulation with the binder polymers. The inlay (filling) of Ag paste in the trench layer of transparent electrode film showed that the variation of electrical resistance was within $10 \%$ upon bending up to 100,000 times to radius of $3 \mathrm{~mm}$.
\end{abstract}

\section{Keywords}

Touch Screen Panel, Silver Paste, Stretchable Substrate Film, UV Imprinting, 
UV Resin Formulation

\section{Introduction}

The automobile displays are becoming an important part of display devices owing to the connected car issue as shown in recent consumer electronics show (CES) and mobile world congress (MWC). Some luxury cars have multiple displays including central information display (CID), rear seat entertainment and head-up displays [1] [2]. Among these, CID is the key display for automobile industry. The touch screen panel (TSP) is widely employed in the CID and its size is gradually increasing [3]. In this study a 12-inch TSP has been fabricated utilizing a flexible and stretchable substrate film. As the size of TSP increases, the indium tin oxide (ITO) film should be replaced with a metal mesh type conducting electrode film due to the high electrical resistance of ITO film [4]. We selected thermoplastic polyurethane film as the substrate film of flexible TSP since the fabrication of TSP module requires curved surface to fit in the CID panel of the automobile. Although the TSPs fabricated on the rigid transparent film like polyethyleneterephthate (PET) films have been widely used, those on transparent flexible and stretchable films have not been reported in depth, especially for automobile displays [5] [6]. The formulation of photosensitive UV resin and silver paste are key materials for the low electrical resistance and high transparency of the TSP for automobile application. The preparation of the two important materials and the application processes have been examined.

\section{Experiments}

The transparent films tested as substrate for metal mesh type conducting electrode films include polyimide (PI-100), thermoplastic polyurethane (TPU-100 and TPU-150), another polyurethane (PU-100) and nylon (Nylon-100), obtained from Kolon Industries, Korea. The UV oligomer and monomers for formulation of photosensitive UV resins are shown in Figure 3, obtained from CCTech. Co., Korea. The binder polymers for the preparation of silver pastes were as following: polyurethane (Ebecryl 8411, Allnex, Sydney, Australia), $\mathrm{M}_{\mathrm{w}}=1000$; Polyester-1 (ES-365, SK Chemical Co., Korea), $\mathrm{Mw}=40,000, \mathrm{~T}_{\mathrm{g}}=16^{\circ} \mathrm{C}$; Polyester-2 (ES-215, SK Chemical Co., Korea), $\mathrm{M}_{\mathrm{w}}=35,000, \mathrm{~T}_{\mathrm{g}}=-10^{\circ} \mathrm{C}$; Epoxy resin (KDN-255, Kukdo Chemical Co., Korea), $\mathrm{M}_{\mathrm{w}} \leq 3000, \mathrm{EEW}=450-500$.

The optical properties of the substrate films and UV imprinted trench layer on substrate film were measured with HR-100 optical instrument. The mechanical properties of the films were measured with Universal Testing Machine (AGX-100N, Shimadzu Co., Japan) instrument. The bending and electrical resistance test of transparent electrode films were conducted with Flexible Endurance Tester (DLDM 111LHA, Yuasa Co., Japan) and Resistance Meter (K-9634FT, MIK21 Co., Korea). The inlay (filling) of the silver paste was carried out with scratching equipment. 
In order to make a TSP for automobile application a metal mesh type electrode film should be fabricated. The process of imprinting the mesh type electrode pattern, UV exposure equipment and schematic diagram of the electrode pattern layer on substrate film are shown in Figures 1(a)-(c), respectively. The photosensitive UV resin is coated on the embossed metal mold and a flexible TPU film is placed on top of the mold. Then a transparent glass is put on the TPU film, followed by rolling of UV resin, UV exposure and demolding.

\section{Result and Discussion}

\subsection{Substrate Films and Properties}

The mechanical and optical properties of the substrate films are important subject of TSP for application to automobile industry. We have chosen five different transparent films including polyimide (PI-100) film, thermoplastic polyurethane films (TPU-100 and TPU-150 the numbers indicate thickness of the film in $\mu \mathrm{m}$ ), another polyurethane film (PU-100) and nylon (Nylon-100) film as candidates. The optical properties of the five films are shown in Figure 2 and Table 1. The optical properties of the five films were similar and all films satisfied the specifications for

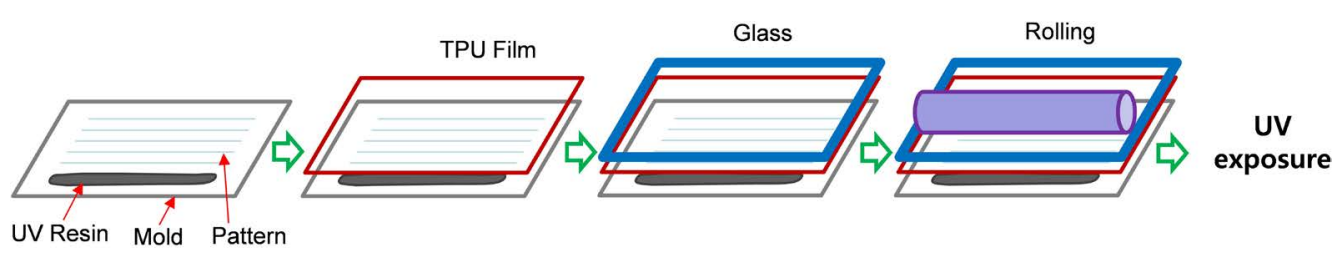

(a) UV imprinting of mesh-type electrode pattern on substrate film with photosensitive UV resin

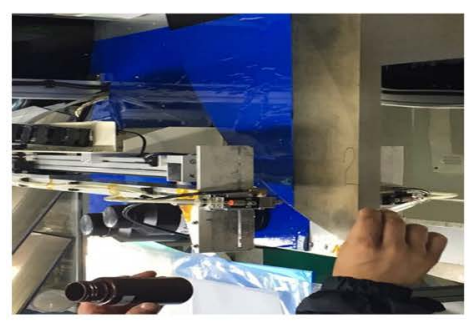

(b) Turn-table type UV exposure

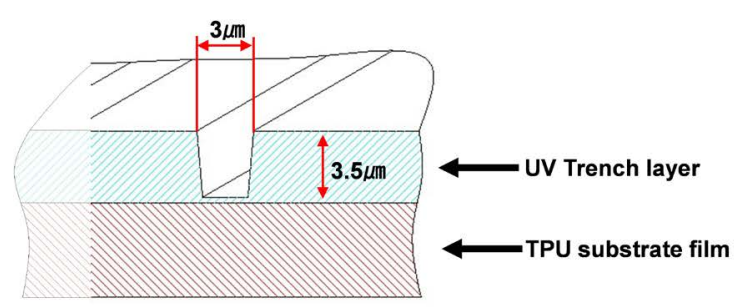

(c) Schematic diagram of electrode layer/substrate film

Figure 1. UV imprinting process of mesh type electrode pattern on the TPU film.

Table 1. The optical (a) and mechanical properties (b) of substrate films.

(a)

\begin{tabular}{cccc}
\hline Film thickness $(\mu \mathrm{m})$ & Transmittance $(360 \sim 740 \mathrm{~nm})$ & Yellow index $\left(\mathrm{b}^{*}\right)$ & Haze \\
\hline Target value & 89 & 2.5 & 3.2 \\
PI (120) & 91.72 & 0.83 & 1.30 \\
Nylon (120) & 92.11 & 0.51 & 1.57 \\
TPU (150) & 92.09 & 0.38 & 1.86 \\
TPU (100) & 92.16 & 0.37 & 1.68 \\
PU (120) & 91.49 & 0.3 & 1.81 \\
\hline
\end{tabular}


(b)

$\begin{array}{ccccc}\text { Film thickness }(\mu \mathrm{m}) & \text { Max. stress } & \text { Elongation }(0.2 \% \text { strain) } & \text { Stress }(0.2 \% \text { strain }) & \text { Elastic recovery } \\ \text { Unit } & \mathrm{N} / \mathrm{mm}^{2} & \mathrm{~mm} & \text { Newton }(\mathrm{N}) & \% \\ \text { PI (120) } & 231.8 & 1.27 & 53.9 & 80.8 \\ \text { Nylon (120) } & 74.0 & 1.27 & 9.1 & 84.8 \\ \text { TPU (150) } & 122.1 & 2.12 & 5.6 & 98.5 \\ \text { TPU (100) } & 78.8 & 2.72 & 4.3 & 89.2 \\ \text { PU (120) } & 82.6 & 1.35 & 3.4 & 97.3\end{array}$

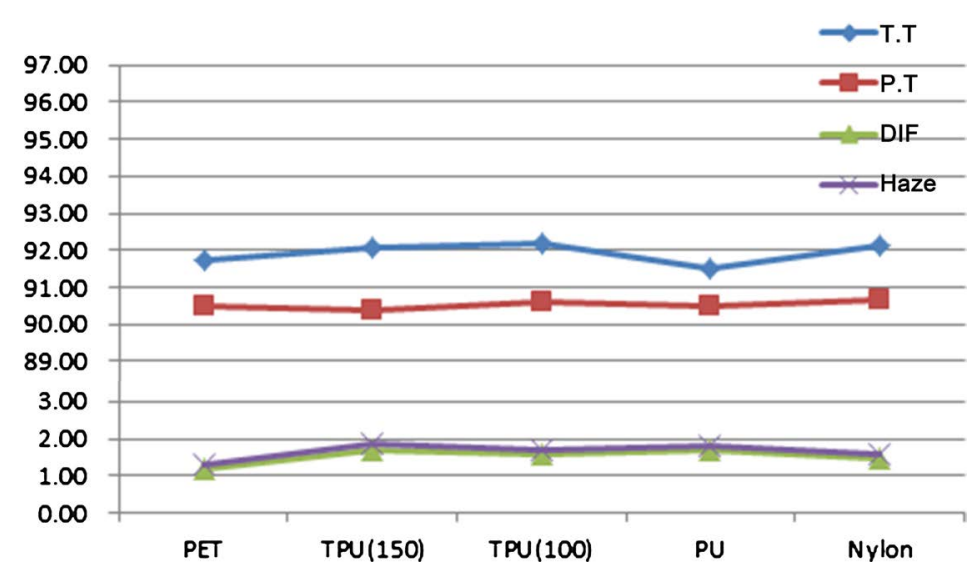

(a)
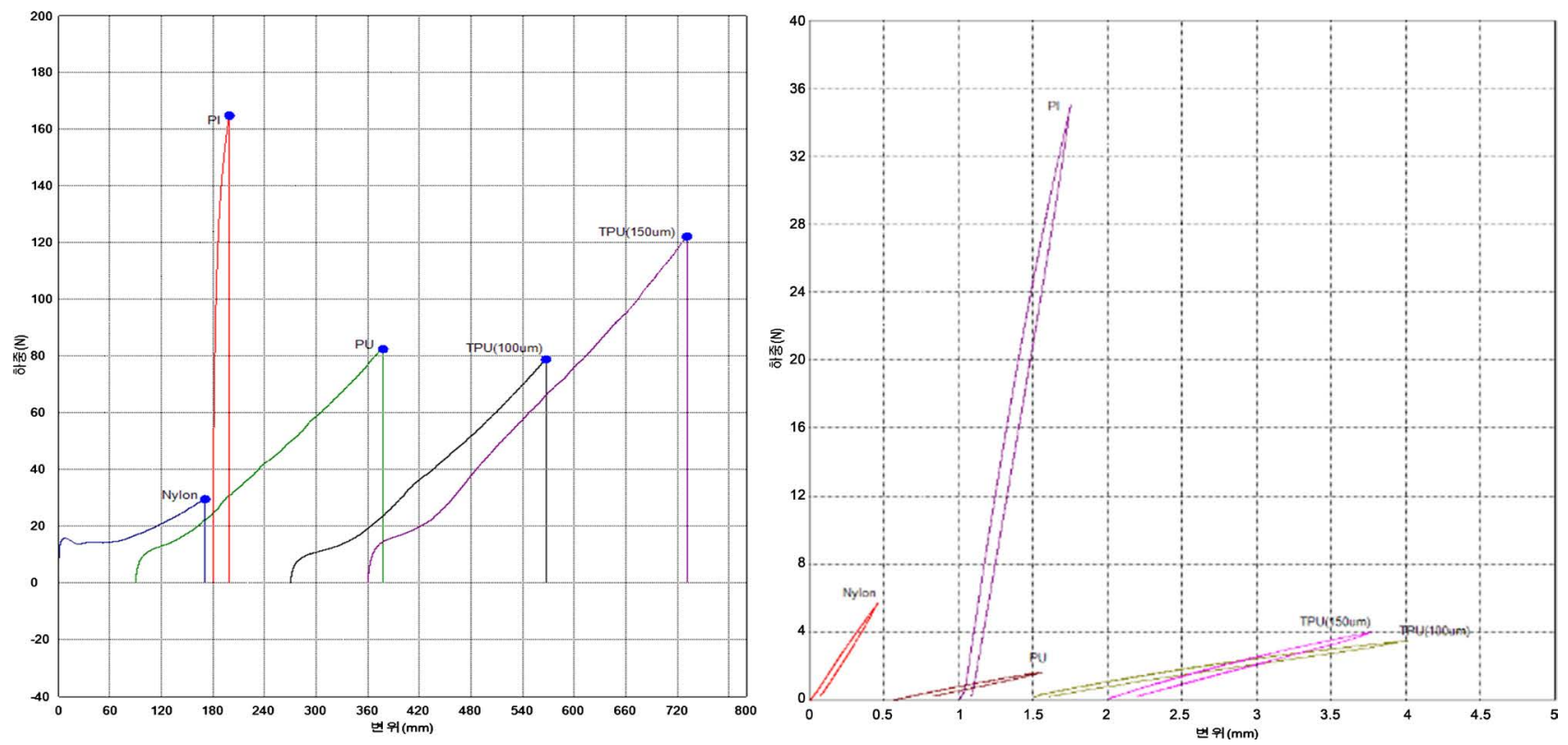

(b)

Figure 2. The optical (a) and mechanical property (b) curves of substrate films.

use in TSP fabrication.

The mechanical properties of the films were quite different as shown in Figure 2(b) and Table 1. Although the mechanical strength of the Nylon and PI films were higher than the PU or TPU films, the elastic recovery of the PU and 
TPU films were better than those of the Nylon and PI films. The TPU-150 film was chosen as the substrate film for flexible and stretchable TSP since it had both high elastomeric recovery (98.6\%) and high Young's modules of 5.63, suitable for the in-mold fabrication process of automobile TSPs.

\subsection{UV Resin Formulation and Properties}

The formulation of UV resin is important in the UV imprinting process due to two reasons. First the UV resin affects the demolding of the substrate film on which fine mesh electrode patterns were formed after UV curing off the embossed metal mold.

Second, the optical and mechanical properties of the substrate film with UV imprinted electrode pattern layer are also dependent on the formulation of photosensitive UV resin. The structures of UV monomers used in the formulation are shown in Figure 3.

In order to check the basic demolding and optical properties of the mesh electrode patterned film, a simple UV resin formulation was prepared which were composed of F-150 polyurethane oligomer, IBOA, 2-EHA and PI-TPO photoinitiator dissolved in 2-HEMA monomer (25 wt\%) as shown in Table 2(a). Here F-150 UV oligomer was included to have a good adhesion to the TPU-150 substrate film. IBOA and 2-EHA monomers were employed to achieve the balance of hard and soft monomers which affect he demolding of electrode patterned TPU film off the metal mold. The test films were obtained in three different ways 1) UV resin only, 2) unpatterned UV resin layer/TPU film and 3) patterned UV resin layer/TPU film by using UV imprinting method as shown in Table 2(b).

From Table 2(b) the two-layer film fabricated with UV imprinted electrode pattern on substrate film exhibited improved optical property compared to the film made with flat (without pattern) UV resin layer on TPU film, especially the optical properties like haze and $\mathrm{b}^{*}$ value. This may be due to the index matching effect of two-layer film and interference of light in the patterned two-layer film.

After confirming that the two-layer films consisted of patterned mesh electrode

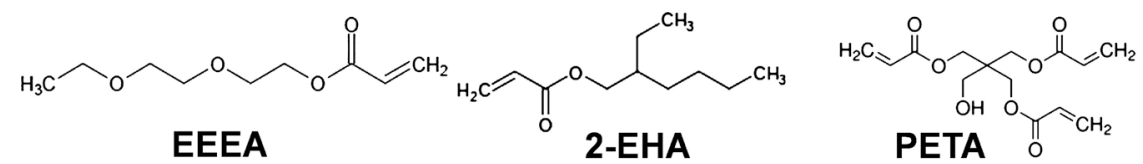

EEEA<smiles>C=CC(=O)OC1CC2CCC1(C)C2(C)C</smiles>
IBOA<smiles>C=C(C)C(=O)OC</smiles>

\section{2-EHA}<smiles>C=CC(=O)OCCO</smiles>

2-HEA<smiles>C=CC(=O)OC</smiles>

MAC<smiles>C=CC(=O)OCCCCCCOC(=O)C=C</smiles>

HDDA<smiles>C=C(C)C(=O)OCCO</smiles>

HEMA

Figure 3. The chemical structures and abbreviations of UV monomers. 
layer on TPU-150 substrate film have good optical property for touch panel use, the mechanical and other process properties of the composite film were examined. Several issues are involved in the relationship among the UV resin formulation and mechanical/process properties of the two-layer film. The improvements of UV resin formulation are explained in Table 3.

Table 2. UV resin formulation (a) and optical properties of films (b) made with 1) UV resin only 2) Unpatterned UV resin layer/TPU film and 3) patterned UV resin layer/TPU film.

(a)

\begin{tabular}{cccccc}
\hline & UV oligomer & \multicolumn{2}{c}{ UV monomer } & Photoinitiator & Total \\
\cline { 2 - 5 } Sample & F130 & IBOA & 2-EHA & $\begin{array}{c}\text { PI-TPO } \\
\text { (\%) }\end{array}$ & \\
\hline UVX-3 & 60 & 35 & & 5 & 100 \\
UVX-4 & 50 & & 45 & 5 & 100 \\
UVX-5 & 50 & 15 & 30 & 5 & 100 \\
\hline
\end{tabular}

(b)

\begin{tabular}{lcccc}
\hline \multicolumn{1}{c}{ Optical Properties } & & Transmittance & $\mathbf{b}^{*}$ & Haze \\
\hline \multicolumn{1}{c}{ Target value } & & 89.0 & 3.20 & 2.50 \\
$\begin{array}{l}\text { Preparation of films for examination of } \\
\text { optical properties: }\end{array}$ & UVX-3 (1) & 93.2 & 2.63 & 2.83 \\
$\begin{array}{l}\text { 1) Film made with UV resin only } \\
\text { 2) Unpatterned UV resin layer/TPU film }\end{array}$ & UVX-3 (2) & 92.7 & 1.93 & 2.08 \\
3) Patterned UV resin layer/TPU film & UVX-4 (1) & 92.6 & 1.99 & 2.15 \\
& UVX-4 (2) & 93.2 & 4.88 & 5.23 \\
& UVX-4 (3) & 92.8 & 2.23 & 2.41 \\
& UVX-5 (1) & 93.5 & 1.92 & 2.07 \\
& UVX-5 (2) & 92.6 & 2.64 & 4.74 \\
& UVX-5 (3) & 92.7 & 2.26 & 2.44 \\
\hline
\end{tabular}

Table 3. The improvement of UV resin formulation for mesh electrode imprinting.

\begin{tabular}{|c|c|c|c|c|c|c|c|c|c|c|c|c|}
\hline \multirow{3}{*}{ Sample } & \multirow{3}{*}{$\begin{array}{l}\text { Improvement } \\
\text { of UV resin } \\
\text { formulation }\end{array}$} & \multicolumn{2}{|c|}{ UV oligomer } & \multicolumn{6}{|c|}{ UV monomer } & \multicolumn{3}{|c|}{ Photoinitiator } \\
\hline & & \multirow{2}{*}{ F150 } & \multirow{2}{*}{ EEEA } & \multirow{2}{*}{ MMA } & \multirow{2}{*}{ MAC } & \multirow{2}{*}{ PETA } & \multirow{2}{*}{ IBOA } & \multirow{2}{*}{ HDDA } & \multirow{2}{*}{ 2-HEA } & \multirow{2}{*}{ 2-EHA } & PI-TPO & \multirow{2}{*}{ (\%) } \\
\hline & & & & & & & & & & & ( $25 w t \%$ in 2 -HEA) & \\
\hline UVX-6 & a) Adhesion, & 50 & & & & & 35 & & 10 & & 5 & 100 \\
\hline UVX-7 & 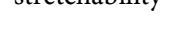 & 40 & 15 & & & & 15 & & 5 & 20 & 5 & 100 \\
\hline UVX-8 & & 20 & 15 & & & & 25 & & 5 & 30 & 5 & 100 \\
\hline UVX-9 & b) Stickiness, & 40 & & 20 & & & 10 & & 5 & 20 & 5 & 100 \\
\hline UVX-10 & $\begin{array}{l}\text { bad smell, } \\
\text { demolding }\end{array}$ & 40 & 5 & & 10 & & 15 & & & 20 & 10 & 100 \\
\hline UVX-11 & & 15 & 2.5 & & & 5 & 37.5 & 20 & & 10 & 10 & 100 \\
\hline
\end{tabular}


In UVX-6, 7, 8 resin formulations, the adhesion of electrode mesh layer on the substrate film was good enough upto $200 \%$ elongation of the double layer film. But the stickiness of the surface of electrode mesh layer was too high after UV curing. This was due to the high amount of soft monomers (sum of EEEA and 2-EHA monomers) which was in the range of $35 \mathrm{wt} \%$ to $45 \mathrm{wt} \%$. So we included a hard monomer, methylmethacrylate (MMA) as shown in UVX-9, but the UV resin containing MMA was found not to be cured by UV exposure upto $150 \mathrm{~mJ}$. This may be due to the steric hindrance effect of methyl group in the MMA monomer during the UV curing process. When the MMA monomer was replaced with methylacrylate (MAC) (UVX-10), the UV curing was found to proceed under a normal UV dose of $100 \mathrm{~mJ}$. However, the adoption of MAC monomer in the UV formulation caused the environmental problem of bad smell. So we reformulated the UV resin without MAC monomer as shown in UVX-11.

The next important task of UV resin formulation was to solve the clean demolding of the two-layer film off the embossed metal mold after UV curving process. The UV resin formulations for this purpose are shown in Table 4. The UV formulation (UVX-11) exhibited good electrode pattern with dimension of 5 $\times 5.5$ (width $\times$ depth) $\mu \mathrm{m}$. When we used the UVX-11 resin formulation to pattern the mesh electrode layer with dimension of $3 \times 3.5 \mu \mathrm{m}$, the electrode pattern after demolding showed some defect as shown in Figure 4.

The difficulty of demolding $3 \times 3.5 \mu \mathrm{m}$ mesh electrode layer on TPU double layer film off the embossed metal mold seemed to be due to the increased interfacial

Table 4. UV resin formulations for improving the demolding of the metal mold with the electrode pattern size of $3 \times 3.5 \mu \mathrm{m}$.

\begin{tabular}{|c|c|c|c|c|c|c|c|c|c|c|c|}
\hline \multirow[b]{2}{*}{ Sample } & \multirow{2}{*}{$\begin{array}{l}\text { Improvement } \\
\text { of UV resin } \\
\text { formulation }\end{array}$} & \multicolumn{2}{|l|}{ UV oligomer } & \multicolumn{4}{|c|}{ UV monomer } & \multicolumn{3}{|c|}{ Photoinitiator } & \multirow{2}{*}{$\begin{array}{c}\text { Total } \\
(\%)\end{array}$} \\
\hline & & F150 & EEEA & PETA & IBOA & HDDA & 2-HEA & 2-EHA & \multicolumn{2}{|c|}{ PI-TPO } & \\
\hline UVX-11 & a) UV & 15 & 2.5 & 5 & 37.5 & 20 & & 10 & 10 & & 100 \\
\hline UVX-12 & exposure & 20 & 7.5 & 5 & 27.5 & 20 & & & 10 & 10 & 100 \\
\hline UVX-13 & b) Demolding & 20 & 7.5 & 5 & 22.5 & 20 & 5 & & 10 & 10 & 100 \\
\hline UVX-14 & $\begin{array}{l}\text { (trench size; } \\
3 \times 3.5 \mu \mathrm{m})\end{array}$ & 20 & 7.5 & 5 & 10 & 20 & 17.5 & & 10 & 10 & 100 \\
\hline UVX-15 & & 20 & 7.5 & 5 & & 25 & 22.5 & & 10 & 10 & 100 \\
\hline
\end{tabular}

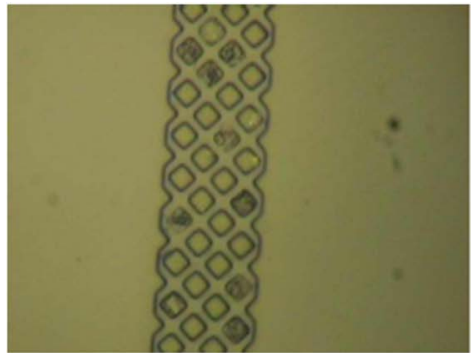

(a)

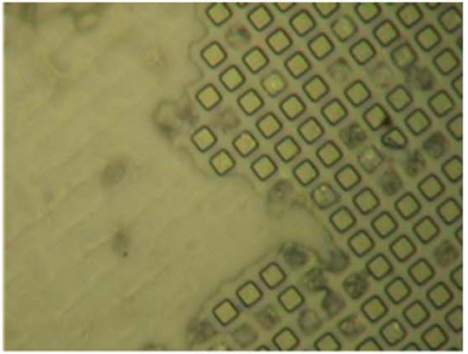

(b)

Figure 4. The engraved electrode pattern (a) narrow bezel part (b) wide bezel part obtained by demolding after UV curing process. 
surface area between the patterned electrode layer and the fine metal mold.

So we first increased the amount of the photoinitiator as shown in UV resin formulation in UVX-12. The demolding of the two-layer film became easier as the amount of photoinitiator was increased, but the complete demolding of clean two-layer film off the metal mold was not achieved. This seemed to be caused by higher amount of hard UV monomer, IBOA in the formulation. So we replaced part of the IBOA hard monomer with neutral monomer 2-hydroethylacrylate (2-HEA) while keeping the amount of the soft monomer (EEEA) $15 \mathrm{wt} \%$ constant. When the amount of IBOA hard monomer was decreased to $10 \mathrm{wt} \%$, the demolding of the two-layer film off the metal mold became clean and complete as shown in Figure 5.

We further improved the UV formulation (UVX-15) by completely removing IBOA monomer and increasing the amount of HDDA cross-linking monomer to $25 \mathrm{wt} \%$. The increase of the photoinitiator and HDDA crosslinking monomer could lead to the complete participation of diacrylate monomers in the crosslinking reaction thus increasing the strength of the double layer film during the demolding process.

\subsection{Ag Paste, Inlay and Electrode Performance}

After establishing the optimum condition for patterning of trench type mesh electrodes, the formulation of $\mathrm{Ag}$ paste and its inlay (filling) into electrode trench $(3 \mu \mathrm{m}$ width) and the properties of the completed transparent conducting electrode film were examined.

First silver nanopowder was synthesized by using aliphatic amine, carboxylic acid as source of surfactant, silver acetate as precursor of Ag nanoparticle and hydrazine as reducing agent of silver ion. After synthesis of the Ag nanoparticles the product suspension was washed with 2-(2-ethoxyethoxy)ethyl acetate (ECA) solvent, and then separated by centrifuge to obtain Ag nanoparticles in a powder form. The TEM images of $\operatorname{Ag}$ nanoparticles $(a, b)$ and the $\operatorname{Ag}$ pastes $(c, d)$ made with the Ag nanoparticles are shown in Figure 6.

The Ag nanoparticles were used to prepare stretchable Ag paste samples by using three different binder polymers (polyurethane, polyester, epoxy resin) and BYK dispersant in ECA/r-butyrolactone $(r-B T L)=50: 50 \mathrm{wt} \%$ mixture solvent as shown in Table 5.

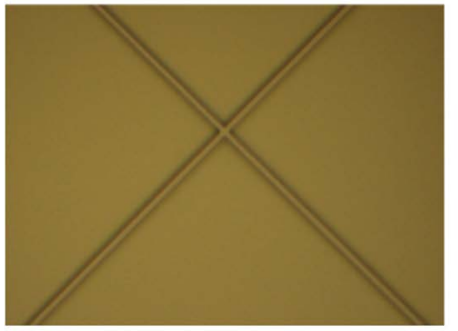

(a)

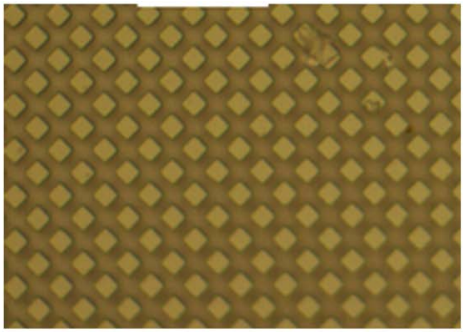

(b)

Figure 5. The engraved electrode pattern (a) sensor part and (b) bezel part of electrode pattern obtained by demolding after UV curing process. 


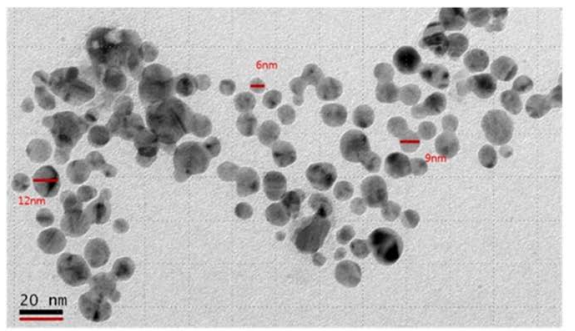

(a) Ag particle size: average $10 \mathrm{~nm}$

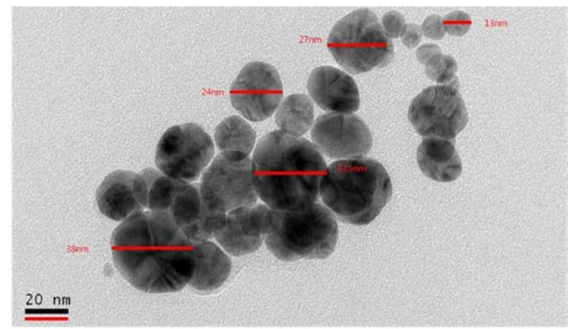

(b) Ag particle size: average $30 \mathrm{~nm}$

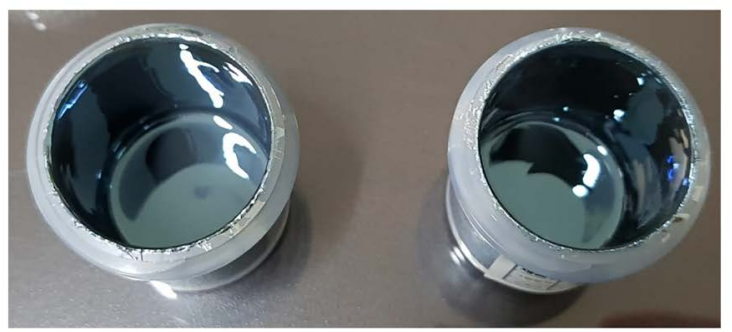

$\begin{array}{ll}\text { (c) Ag (avg. } 10 \mathrm{~nm}) \text { paste } & \text { (d) } \mathrm{Ag}(\text { avg. } 30 \mathrm{~nm} \text { ) paste }\end{array}$

Figure 6. TEM images of Ag nanoparticles and camera images of Ag pastes.

Table 5. Formulation of Ag paste for selection of binder polymer. ${ }^{1}$

\begin{tabular}{cccccc}
\hline \multirow{2}{*}{ Ag Ink } & \multicolumn{2}{c}{ Ag nanoparticles } & & Solvent & Additive \\
\cline { 2 - 3 } & $\mathrm{Ag}(10 \mathrm{~nm})$ & $\mathrm{Ag}(30 \mathrm{~nm})$ & & Binder polymer & \\
\cline { 5 - 6 } AgP-1 & 8.8 & 70.2 & Polyurethane: 4.0 & 16.0 & 1.0 \\
AgP-2 & 8.8 & 70.2 & Polyester-1: 4.0 & 16.0 & 1.0 \\
AgP-3 & 8.8 & 70.2 & Polyester-2: 4.0 & 16.0 & 1.0 \\
AgP-4 & 8.8 & 79.2 & Epoxy resin: 4.0 & 7.0 & 1.0 \\
\hline
\end{tabular}

${ }^{1}$ Formulation of Ag paste is based on wt\%. ${ }^{2}$ Binder polymers: polyurethane (Ebecvyl 8411, Allnex, Sydney, Australia), $\mathrm{Mw}=1,000$; Polyester-1 (ES-365, SK Chemical Co., Korea), $\mathrm{Mw}=40,000, \mathrm{~T}_{\mathrm{g}}=16^{\circ} \mathrm{C}$; Polyester- 2 (ES-215, SK Chemical Co., Korea), $\mathrm{Mw}=35,000, \mathrm{~T}_{\mathrm{g}}=-10^{\circ} \mathrm{C}$; Epoxy resin (KDN-255, Kukdo Chemical Co., Korea), $\mathrm{Mw} \leq 3000$, EEW $=450-500 .{ }^{3}$ Solvent: r-BTL (r-butylzolactone). ${ }^{4}$ Additive: BYK-180 (BYK Co., Germany).

The Ag pastes in Table 5 were tested by screen printing on the newly made stretchable polyurethane film of thickness $150 \mu \mathrm{m}$ (utilizing the Clear Flex $30 \mathrm{~A}$ and B resin obtained from Smmoth-on Inc., U.S.A.) on which crosslinked polyester masking layer was coated to a thickness of $3 \mu \mathrm{m}$ according to the author's previous work [7]. After screen printing the polyurethane film with polyester masking layer, the electrode pattern was cured thermally at $130^{\circ} \mathrm{C}$ for $30 \mathrm{~min}$ in a convection oven to give dry Ag electrode pattern with thickness of $30 \mu \mathrm{m}$. The electrical resistance vs. the strain plots of Ag electrode pattern $(30 \mu \mathrm{m})$ screen printed on the polyester masking layer $(3 \mu \mathrm{m}) /$ Clear Flex polyurethane $(150 \mu \mathrm{m})$ double-layer film is shown in Figure 7(a). The Ag paste with polyester as binder polymer showed moderate increase of electrical resistance upto $150 \%$ strain while the Ag pastes with epoxy or polyurethane as binder polymer showed very high resistance values. The optical microscopic images of screen printed Ag pastes with epoxy or polyurethane as binder polymer exhibited micro-cracks 


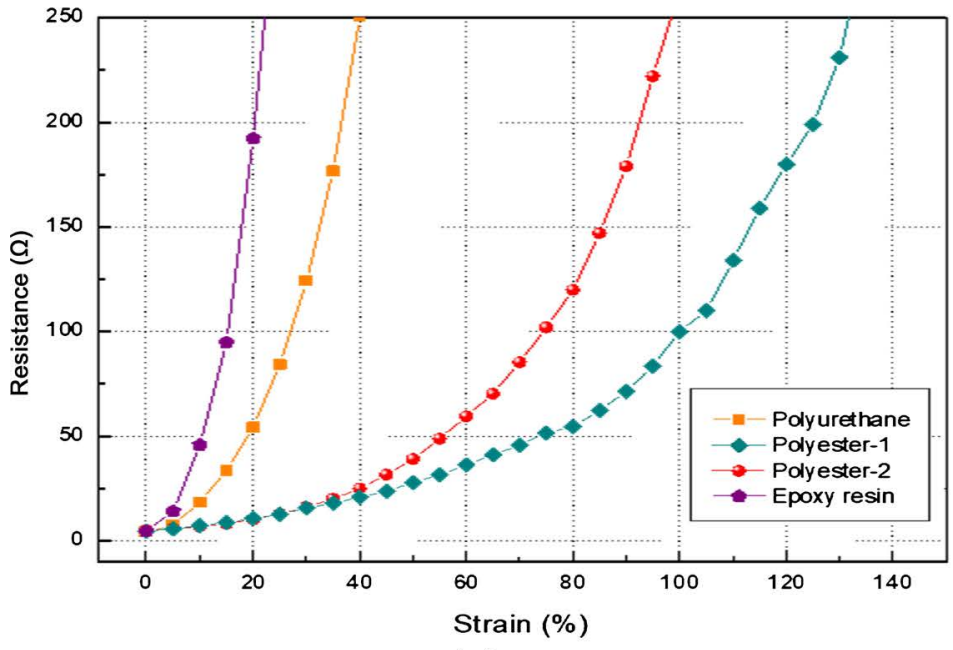

(a)

over $100 \%$ strain while $\mathrm{Ag}$ pastes with polyester binders showed no cracks upto $150 \%$ strain (Figure 7 (b)) [8].

The Ag paste with polyester-1 binder polymer (AgP-2) showed wider strain range than AgP-3 paste with polyester-2 from Figure 7. However, the adhesion of $\mathrm{Ag}$ paste with polyester-2 binder polymer (AgP-3) to the substrate film was better than that of $\mathrm{Ag}$ paste with polyester-1 binder, thus polyester- 2 was selected as binder polymer of Ag paste.

Having selected the polyester-2 as binder polymer we further modified the formulation of $\mathrm{Ag}$ pastes for the low electrical resistance and good adhesion to mesh electrode layer. The good adhesion of Ag paste to the trench layer made of UVX-15 resin is important because the depth of Ag paste filled in the trench layer is less than $3.5 \mu \mathrm{m}$ which is labile to the strain deformation. The modification of Ag pastes is shown in Table 6. Here the Ag pastes (Ag T-1 and Ag T-2) showed lower electrical resistance than Ag T-3 paste. The electrical resistance usually decreases with the increasing $\mathrm{Ag}$ nanoparticles and decreasing binder polymer which is a non-conductor. It was noted that the effect of decreasing the

Figure 7. The surface resistance vs. strain curves (a) and optical microscope images (b) of the screen printed Ag pastes made with formulations in Table 5 .

Table 6. Silver paste formulations and evaluation for low electrical resistance and high adhesion to the trench layer surface.

\begin{tabular}{|c|c|c|c|c|c|c|c|}
\hline \multirow{2}{*}{$\begin{array}{l}\text { Ag Ink } \\
\text { Pastes* }\end{array}$} & \multicolumn{2}{|c|}{ Ag nanoparticles } & \multirow{2}{*}{$\begin{array}{l}\text { Binder Polymer: } \\
\text { Polyester-2 }\end{array}$} & \multirow{2}{*}{$\begin{array}{c}\text { Solvent } \\
\mathrm{ECA} / \mathrm{r}-\mathrm{BTL}=50 / 50\end{array}$} & \multirow{2}{*}{$\begin{array}{l}\text { Additive } \\
\text { BYK-180 }\end{array}$} & \multicolumn{2}{|c|}{ Evaluation } \\
\hline & $\mathrm{Ag}(\mathrm{d}=10 \mu \mathrm{m})$ & $\mathrm{Ag}(\mathrm{d}=20 \mu \mathrm{m})$ & & & & $\begin{array}{c}\text { Electrical Resistance } \\
\text { ( } \Omega / \text { square })\end{array}$ & Adhesion \\
\hline Ag T-1 & 8.8 & 70.2 & 2.0 & 18 & 1.0 & $4-5$ & $\mathrm{X}$ \\
\hline Ag T-2 & 8.8 & 70.2 & 3.0 & 7 & 1.0 & $4-5$ & $\mathrm{O}$ \\
\hline Ag T-3 & 8.8 & 79.2 & 4.0 & 7 & 1.0 & $8-10$ & $\mathrm{O}$ \\
\hline
\end{tabular}

*The amount of components are expressed in wt\% unit. 
binder polymer was stronger than increasing the Ag nanoparticles from Table 6 . The comparison between AgT-1 and AgT-2 pastes also indicated that there is a limit to the decrease of binder polymer which could not guarantee the adhesion to the trench layer surface.

After optimizing the Ag paste formulation for inlay (filling) into the trench layer, the Ag paste (AgT-2) was filled in the trench layer by using scratching machine. Figure 8 shows that the Ag paste was filled well in the trench layer both in the sensor part and bezel part.

The variation of electrical resistance of the Ag paste (AgT-2) filled electrode film upon bending to $3 \mathrm{~mm}$ radius upto 100,000 times was $8.8 \%$ (the specification 10.0\%) as shown in Figure 9.

This basic research on the materials and process of metal mesh type TSP fabrication will be a sound foundation for use in the automobile display industry.
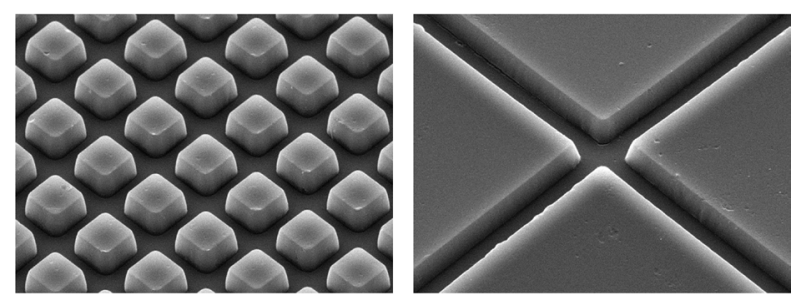

(a)
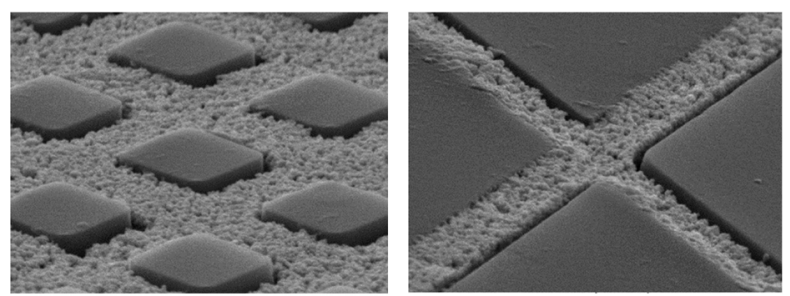

(b)

Figure 8. The SEM images of empty trench layer pattern (a) and filling (inlay) of Ag paste in the trench layer (b).
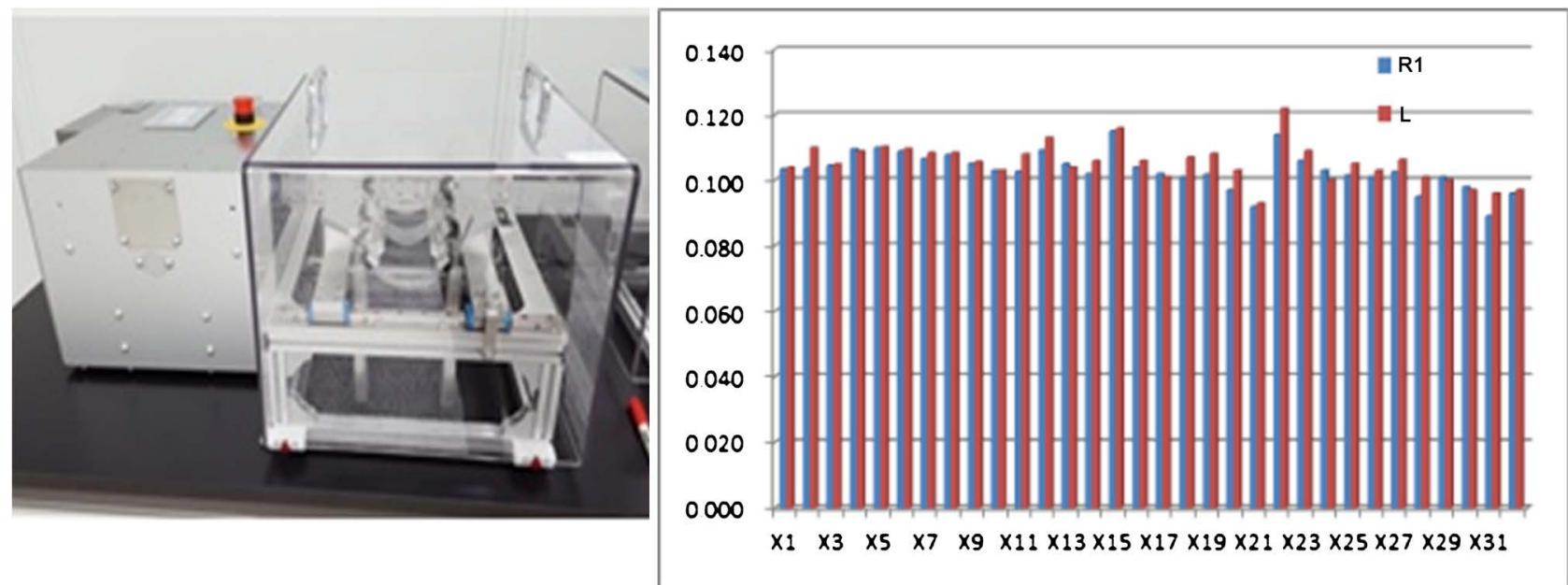

Figure 9. Bending test equipment and the variation of electrical resistance of Ag paste filled electrode film after 100,000 times, 3 $\mathrm{mm}$ radius bending test. 


\section{Conclusion}

Touch screen panels (TSPs) for automobile application require a flexible and stretchable substrate film. In this work a thermoplastic polyurethane film was selected as a substrate film for fabrication of mesh type electrode patterns by using photosensitive UV resin. In the mesh electrode patterning the balance of hard and soft monomer in addition to the balance of multifunctional monomer and monofunctional monomer were found important for the optical and mechanical properties of UV resin formulation, especially the demolding process after UV curing off the finely patterned metal mold. It was also noted that the formulation of silver pastes is very important for the inlay process and balance between the low electrical resistance and bending test up to 100,000 times with radius of $3 \mathrm{~mm}$. The nano-sized silver particles were found to give the low electrical resistance of $4-5 \Omega$ /square in combination with the polyester binder polymer with high molecular weight $(\mathrm{Mw}=35,000 \mathrm{~g} / \mathrm{mol})$ and low glass transition temperature $\left(\mathrm{T}_{\mathrm{g}}=16^{\circ} \mathrm{C}\right)$.

\section{Acknowledgements}

This material is based upon work supported by the Ministry of Trade, Industry \& Energy (MOTIE, Korea) under Industrial Technology Innovation Program "Development of Stretchable Transparent Electrode Film with $3 \mu \mathrm{m}$ Line Space Based on Cu/Ag Composite Nanoparticles" (No. 10062220).

\section{Conflicts of Interest}

The authors declare no conflicts of interest regarding the publication of this paper.

\section{References}

[1] Sun, M. and Yu, H. (2019) Automobile Intelligent Dashboard Design Based on Human Computer Interaction. International Journal of Performability Engineering, 15, 571-578. https://doi.org/10.23940/ijpe.19.02.p21.571578

[2] Qiu, C., Liu, Z., Wang, K. and Sun, X. (2018) 34.1: Invited Paper: Application of Display Technology in Automobile. Society for Information Display, 49, 364-366. https://doi.org/10.1002/sdtp.12728

[3] Haga, H., Sugimoto, D., Yang, Y., Sasaki, H., Asai, T. and Shigemura, K. (2019) Capacitive Touchscreen-Integrated Electrostatic Tactile Display with Localized Sensation. Society for Information Display, 27, 59-71. https://doi.org/10.1002/jsid.748

[4] Hamasha, M.M., Dhakal, T., Alzoubi, K., Albahri, S., Qasaimeh, A., Lu, S. and Westgate, C.R. (2012) Stability of ITO Thin Film on Flexible Substrate under Thermal Aging and Thermal Cycling Conditions. Journal of Display Technology, 8 , 385-390. https://doi.org/10.1109/JDT.2011.2176532

[5] Choi, Y.-M., Kim, K.-Y., Lee, E., Jo, J. and Lee, T.-M. (2015) Fabrication of a Single-Layer Metal-Mesh Touchscreen Sensor Using Reverse-Offset Printing. Journal of Information Display, 16, 37-41. https://doi.org/10.1080/15980316.2014.991770

[6] Kim, K., Hyun, B.G., Jang, J., Cho, E., Park, Y.-G. and Park, J.-U. (2016) Nanomaterial-Based Stretchable and Transparent Electrodes. Journal of Information Dis- 
play, 17, 131-141. https://doi.org/10.1080/15980316.2016.1240111

[7] Nam, H.M., Seo, D.M., Yun, H.D., Thangavel, G., Park, L.S. and Nam, S.Y. (2017) Transparent Conducting Film Fabricated by Metal Mesh Method with Ag and Cu@Ag Mixture Nanoparticle Pastes. Metals, 7, 176.

https://doi.org/10.3390/met7050176

[8] Lim, C.K., Lee, Y.S., Choa, S.H., Lee, D.Y., Park, L.S. and Nam, S.Y. (2017) Effect of Polymer Binder on the Transparent Conducting Electrodes on Stretchable Film Fabricated by Screen Printing of Silver Paste. International Journal of Polymer Science, 2017, Article ID 9623620. https://doi.org/10.1155/2017/9623620 